University for Business and Technology in Kosovo

UBT Knowledge Center

UBT International Conference

2013 UBT International Conference

Nov 2nd, 2:30 PM - 2:45 PM

\title{
Effects of Buildings and Environment in Our Everyday Life
}

Arlinda Sheqiri

University for Business and Technology, arlinda.sheqiri@ubt-uni.net

Follow this and additional works at: https://knowledgecenter.ubt-uni.net/conference

Part of the Architecture Commons

\section{Recommended Citation}

Sheqiri, Arlinda, "Effects of Buildings and Environment in Our Everyday Life" (2013). UBT International Conference. 20.

https://knowledgecenter.ubt-uni.net/conference/2013/all-events/20

This Event is brought to you for free and open access by the Publication and Journals at UBT Knowledge Center. It has been accepted for inclusion in UBT International Conference by an authorized administrator of UBT Knowledge Center. For more information, please contact knowledge.center@ubt-uni.net. 


\title{
Effects of Buildings and Environment in Our Everyday Life
}

\author{
Arlinda Sheqiri \\ University for Business and Technology \\ Department of Architecture and Spatial Planning, Kosovo \\ arlinda.sheqiri@ubt-uni.net
}

\begin{abstract}
Abs tract. This article investigates effects of buildings and environment in our everyday life process. A building and its environment will determinate how people lives and how happy they will be. When it comes to a special type of buildings like Kindergarten, Schools this issue becomes even more delicate and complex. The complexity that those types of buildings bear to itself is really national responsibility and should take all attention not only by municipality, governance, politics, but even by society itself. Th is article will explore the effects of the buildings and environment on children's well being, and education. Schooling has direct effects on children's educational achievement, the quality of education they will get there will influence the society in the future. We have to view learning as a life-long process. The influence that environment and building has on psychological, physical,social and emotional aspects. Education that those children will gain will impact their actions and values on their lives as well as the lives of others, the environment and the world we live in.
\end{abstract}

Keywor ds: Building and environment effects, education, wellbeing

\section{Building and environment effects}

The struggle after 1999 was so visible gap of settling rules and priorities was so difficult, conflict from earliest times has been part of all this process. But even now thirteenth years after it, we see conflicts between greed individuals and suffering society. The specific blend of experiences, abilities, attitudes, and aspirations, that helps to define us, can sit sometimes uncomfortably alongside of our culture and education. My focus was on Primary School, one of several examples that you can see today in Kosovo. The first example is Primary school Naim Frasheri in Podujevo Kosovo. The role of schooling in a society is strength of present and the future of a nation. My research is divided on surrounding environment, building and current situation of offering requirement that a primary school should fulfill. This primary school accommodate 1600 pupils from first grade up to ninth and it has 78 teachers. The facilities of the school are: 17 classrooms, 3 small offices, teachers classroom and 4 sharing toilets for all pupils and teachers.After 1999 the school was damaged from the war and non of mayors that has lead this city till now, didn't take the effort to find a donation to re-built or repair this half destroyed (ghost) building. The pity situation goes far beyond what the words could explain. Starting fromoutside to inside it gives you the feeling of abondance place rather than a school.

\subsection{Model and Data (primary school Naim Frasheri)}

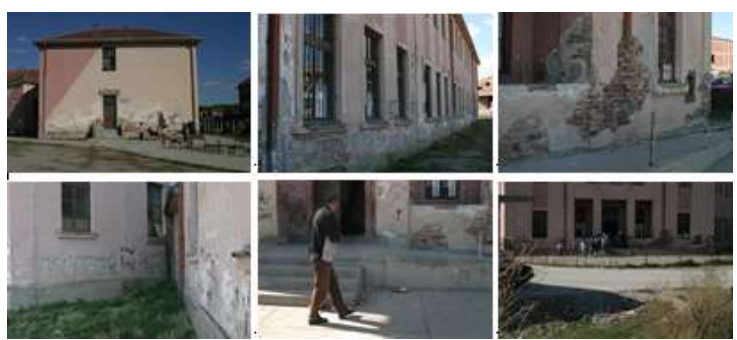

Fig.1 Exterior view of the building 
Photos on figure 1.1 shows the damage of walls to the broken windows, from each part of the building there wasn't a site that wasn't destroyed. The building seems hopeless of possibilities to renovate.

The situation becomes worst during the winter where the cold can come from every damaged site of the building. And the question can be framed; is this Learning Environment?
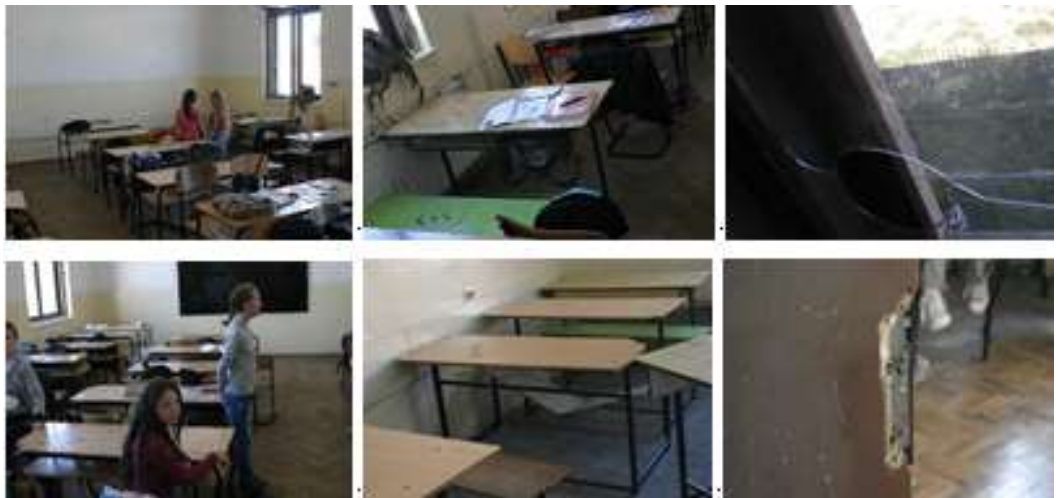

Fig.2 Classrooms

Classrooms as exterior of the building are in a miserable situation, all the classes were almost in the same condition. As we can see on figure 1.2.
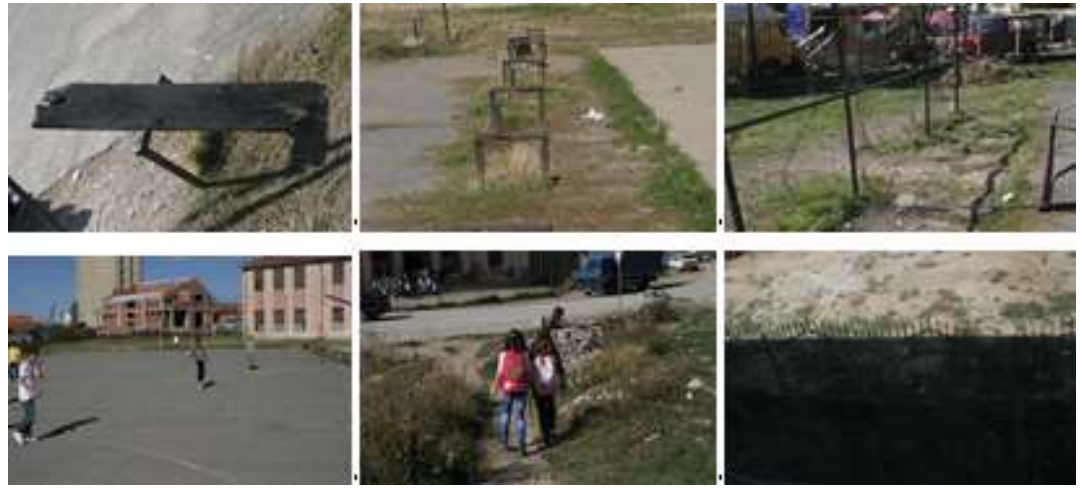

Fig.3 Surrounding environment

Many schools are still nowhere near meeting the goal of universal primary education. Thousands of children who do complete primary school do so with low levels of reading, writing and numeracy due to the poor quality of education they receive. There is much still to be done to ensure every child receives a high quality education and Primary Education. Being in a classroom with a lack of recourses might adversely impact children's mental health because children are frustrated or disheartened by their surroundings. Teachers also may be more discouraged or harsh when they can't teach properly due to the fact that they are missing basic equipments for teaching.

Besides this physical, psychological and emotional effects that those environments cause it will cost with the future of this country. Do their parents really care about their children's mental health - their emotional and behavioral well-being and education on this informal school? And we as society don't tend to focus on that as as important educational outcome nearly as much as much as we talk about and think about academic outcome. If a plant doesn't have root we can't expect for blossoms or long life living. 


\section{How a Primary School should be}

Table. 1. Describe what a primary school should contain and some technical details.

What a primary school should have?

1. Administration ( staffroom meeting room plus staff library, office for headteacher, office for deputy head, office, rooms for meeting parents, doubles as sickroom)

2. Class rooms

3. Supplementary classrooms

4. Hall

5. Rest room

6. Lobby

7. Extra-large classroom (history, geography)

8. Science room ( for preparation, demonstrations \& practicals for physics, chemistry and biology)

9. Classroom for crafts \& materials

10. Classroom for music

11. Cloakroom

12. Classroom for art(drawing tables \& materials)

13. Library

14. Sport room (for different activities)

15. Toilets

16. Playground

17. Parking for Bicycle and limited number of car park

a. Classrooms: one classroom per class, square if possible, in exceptional cases rectangular, max.32 pupils, min. of $65-70 \mathrm{~m} 2$ (approx $2.00 \mathrm{~m} 2 \times 2.20 \mathrm{~m} 2$ per pupil) if possible daylight on two sides. Furniture either in rows or informally arranged.

b. Front of class: chalkboard with sliding planes, projection space, socket for TV, radio, tape recorder, etc., wash-basin near entrance. Provision for hanging maps. Facilities to black out windows. Group rooms divided into separate workspaces to accommodate mixed ability classes only in special cases.

c. Alternatives to individual classes and group rooms: 2-3 classrooms joined together to make teaching spaces for discussions between pupils and teachers, or lessons in larger groups; can also be divided by partitions. Draught-excluding lobbies and entrance area also connect to horizontal and vertical circulation (corridors, stairs, ramps) and can be used during breaks $(0.50 \mathrm{~m} 2)$.

d. Multi-use area for play, exhibitions, or cultural activities.

e. Room for teaching materials centrally positioned, part of the staff area or in the multipurpose room.

f. Cloakroom facilities can be decentralized by allocating space outside of classrooms but directly linked to them.

g. The number of toilets, urinals and wash-basins required based on total number of pupils and separated according to gender.

h. Science rooms includes rooms for teaching of theory and practice, practicals, preparation and collections. Clas srooms forbiology, physics and chemistry $2.50 \mathrm{~m} 2 /$ place. For lectures and demonstration in practical work $4.50 \mathrm{~m} 2 /$ place including space-purpose. 
Education experts maintain that, during conscious learning, people best retain information that they have obtained themselves, more precisely:

a) $100 / 0$ of what they read;

b) $200 / 0$ of what they hear;

c) $300 / 0$ of what they see;

d) $500 / 0$ of what they hear and see;

e) $700 / 0$ of what they say themselves; and

f) $900 / 0$ of what they do themselves involving their own actions.

\subsection{Examples of Primary School}

How a primary school should be? Primary school (WIS) in Wroclaw is a good example to explain the requirements that a school should fulfill, photos are copyright of (WIS).
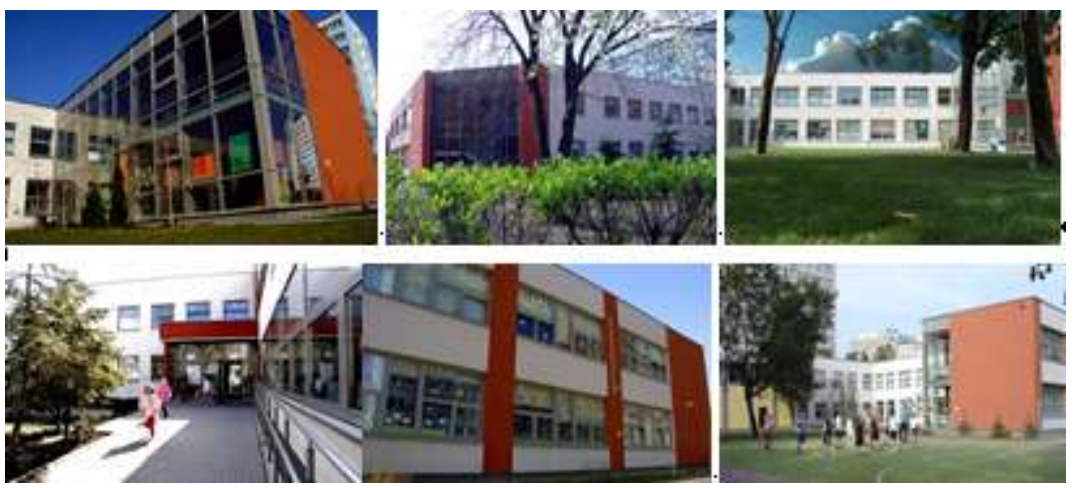

Fig.4 Exterior of the building and its surrounding environment

Warm welcome environment which can be seen even from outside, clean surrounding environment and playground for pupils. An unclean schools and environment poses serious risks to mental as well as physiological health.. There are numerous health benefits of cleaning and from children to adults, all need a clean and healthy environment to grow, work and live.

Productivity of the mind and body increases immensely when one learn and stay in clean and healthy environment. Surrounded by a mess, children and teachers feel stressed and under pressure while working in a fresh and open environment keeps them fresh. Cleaning is imperative for a healthy children and healthy body. It is important to keep surroundings clean and free of disease causing agents as it has numerous health benefits and leads to a happy life.

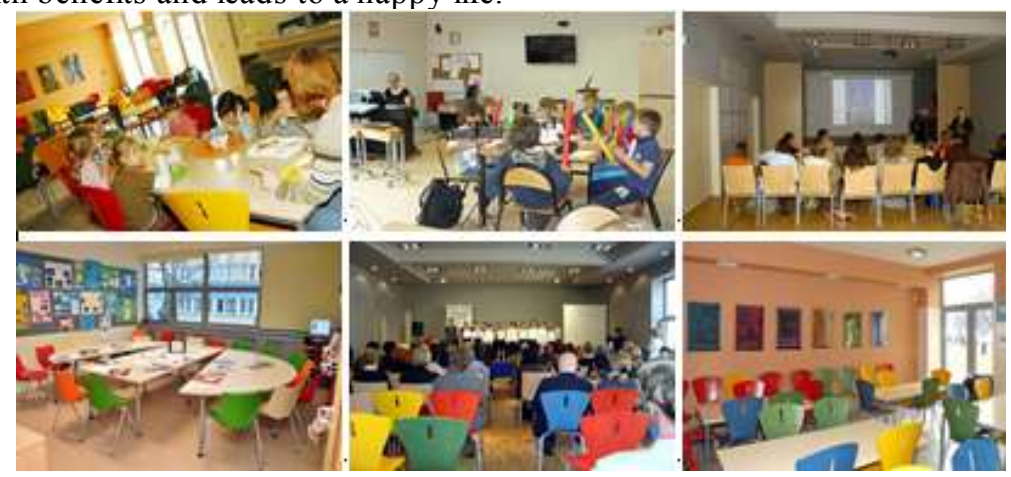

Fig.5 Classrooms

Besides clean and good arrangement color play an important effect in the psychological learning environment and is a major element in interior design that impacts pupils achievement, as well as teacher 
effectiveness and staff efficiency. Specific colors and patterns directly or indirectly influence the emotions, health, behavior, morale, and performance of pupils, depending on the individual's culture, age, gender, and developmental level. From space, form, texture and light even color in interior can have a major role on design element than can be used to create a good learning environment.
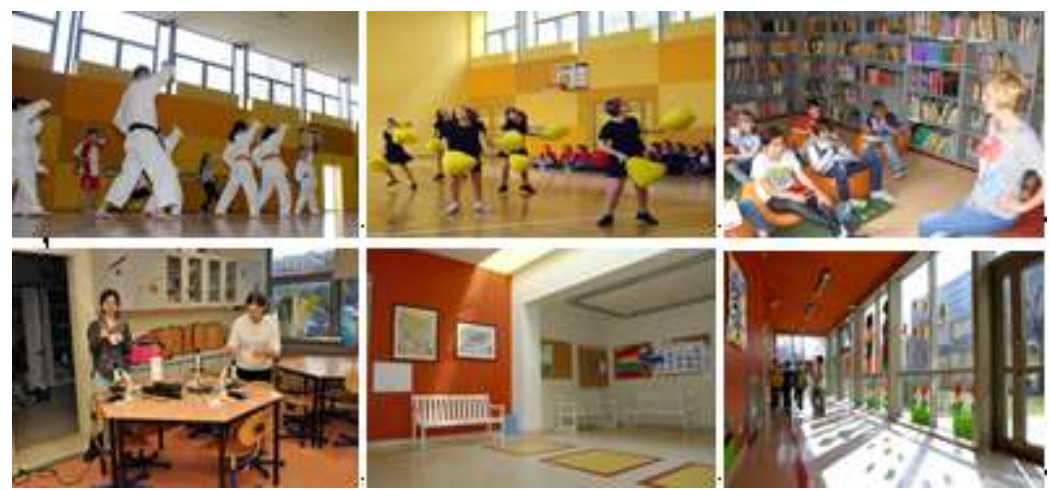

Fig.6 Hall, Library, Sport room

\section{Conclusions}

Based on my research I conclude that, this primary school is informal school and doesn't fulfill any of criteria for considering a usable building. More than anything else is dangerous place for mental, physical,social and emotional aspects of pupils to stay on this informal building. Everything is inappropriate for an educative environment. However even renovation is questionable because the building is too old and damaged, it may be risky.

\section{References}

1 EVIDENCE-BASED DESIGN of Elementary and Secondary Schools, AUTHOR Peter C.Lippman, Published by John Wiley \& Sons, Inc, Hoboken, New Jersey.

2 Creating Innovators: The Making of Young People Who Will Change the World AUTHOR Tony Wagner

3 Ernst and Peter Neufert Architects' Data, Edited by Bous maha Baiche and Nicholas Walliman 